\title{
Ability of innovative human capital to support economic growth in central district of Yunnan province
}

\author{
Linlin Sun ${ }^{1, a^{*}}$ \\ ${ }^{1}$ Yunnan Normal University Business School, Kunming, Yunnan Province, 650106,China \\ aemail: fanxi0529@sina.com
}

Keywords: Human capital; Yunnan gathering area; Competitiveness

\begin{abstract}
Human capital is a key factor in modern economic development, improving the competitiveness of the industry gathering area also has an important role. First, an overview of the basic theory, the study provides a theoretical support. Finally, the accumulation of human capital, configuration, and incentives put forward some suggestions to improve the competitiveness of industry gathering in Central area. Economic development of the economic zone in central Yunnan has been the dominant force in the economic development of Yunnan Province, and the integration of economic progress in Central City area has an important role in its economic development. Spatial Information Integration in Central City and its economic zone between relevant. Therefore, from the perspective of regional economic ties, taking the urban space in Central City linked to capacity as the starting point, Gravity correction model in Kunming, Qujing, Yuxi, Chuxiong space contact was the ability to measure, analyze and from cities in Central City under the influence of the elements of spatial connection status and the ability to link the ability of space to make recommendations about the city location, infrastructure regional division of labor, industrial layout, regional cooperation of the executive branch.
\end{abstract}

\section{Introduction}

Industry gathering area is defined by the government of unified planning business is relatively concentrated area, there are high-tech Development Zone, Technology Park, the processing trade park, modern service park, efficient agriculture parks $[1,2]$. Setting industry gathering area starting point is the intensive use of resources and improve the overall efficiency. Formation mechanism industries gathered competitiveness: First, focus on geography external capable of generating external economies of scale and reduce the production costs of enterprises, gain a competitive advantage [3]. Second, the industry gathering area with flexible specialization, such as within an industrial park through subcontracting and collaboration products, formed a complete industrial chain, enhance the overall competitiveness [4]. Third, the business industry because of competition enclave of continuous learning and innovation, and due to the proximity and shared cultural background space industry, gathering area in favor of technology dissemination and diffusion, thereby enhancing competitiveness; Fourth, industry track enclave development has path dependence, that once you choose a certain system and technology, it has the inertia of development and self-reinforcing effect of amplification, so that competitive advantage is further strengthened [5-8].

A number of studies show that human capital can improve the competitiveness of the industry gathering area, and its mechanism of action is as follows: first, to improve the productivity of human capital industry gathering area, with the improvement and increase the level of human capital, if other conditions ( such as machinery and equipment) are the same, can greatly improve labor productivity; declining development of modern industry gathering area demand for material resources, land, capital, currency, and the demand for talent, research institutions, R \& D, etc. is increasing, human resources has become the most important strategic resource, its quantity and quality directly determines the competitiveness of the industry gathering area. Second, to enhance human capital and innovative industry gathering area, including system innovation, management innovation and technological innovation, promote mutual interaction of these three areas, thereby enhancing the 
competitiveness of industry gathering area. Third, human capital, promoting brand industry gathering area formed by the accumulation of human capital, industrial agglomerations of product quality and product quality will continue to improve, gradually formed brand, highlighting the market differentiated products, help improve competitiveness $[9,10]$.

\section{Urban agglomeration spatial information analysis}

In order to complete the planned development goals, improve industrial competitiveness, enhance scientific and technological innovation, industry gathering in Central District must pay attention to the important role of human capital. In this regard the following recommendations: First, to accelerate the accumulation of human capital industry gathering in Central area. Develop appropriate measures and preferential policies to encourage and guide the industry gathering area businesses, organizations and individuals to invest in human capital; promoting the gathering area outside the continuous inflow of human capital, strengthen exchanges and cooperation with universities, research institutes, formulate preferential policies to attract talent. Guarantee the movement of persons and the legitimate interests of both the employer; establish and improve the human capital market service system to ensure the smooth channels of human capital; to ensure open and fair competition mechanism, the implementation of survival of the fittest assessment mechanism, so that "utilized, can make the best use". Third, encourage industry gathering in Central area of human capital function. Improve human capital equity system, strengthen effective incentives for human capital; build a reputation and restraint mechanisms, such human capital owners value their professional reputation, restrain their behavior; create a "people-oriented" excellent soft environment, improving working industry gathering area conditions and facilities, and provide a stage to display their talent, knowledge and protection of innovation, mobilizing human capital performance play initiative.

Between urban gravity model most commonly used to quantify spatial ability to contact:

$$
P_{i j}=\frac{\sqrt{P_{i} V_{i}^{*} P_{i} V_{j}}}{D_{i j}{ }^{2}}
$$

Where: $\mathrm{Pi}, \mathrm{Pj}$ respectively refers to the number of cities $\mathrm{i}$ and $\mathrm{j}$ are each urban resident population; $\mathrm{Vi}, \mathrm{Vj}$ is the quality indicators $\mathrm{i}$ and $\mathrm{j}$ urban cities: usually $\mathrm{i}$ and $\mathrm{j}$ city urban GDP industrial output; Dij is to refer to the distance between cities $i$ and $j$ of the city.

Increase the convenience of urban transport is the main means to enhance the ability of contact between urban space, modern transportation, especially between urban and highway construction vehicles moving on the link between urban space has the ability to enhance the leading role. Accordingly, the above-described conventional gravity model should make certain changes, to join two of the factors affecting urban traffic. It can be referenced in the calculation of the gravity model of accessibility factor, accessibility refers to people between the two cities, material and information flows within easy reach of the severity index, the higher the accessibility factor, indicating that between two cities various exchanges more convenient, calculated up coefficient as follows:

$$
\begin{aligned}
& A=\frac{1}{n} \sum_{i=1}^{n} A_{i} \\
& a_{i}=A / A_{i}
\end{aligned}
$$

Thus amended, the space between the contact force can be used herein city quantization model is as follows:

$$
P_{i j}=a_{i j} * \frac{\sqrt{P_{i} V_{i}^{*} P_{i} V_{j}}}{D_{i j}{ }^{2}}
$$




\section{Urban spatial information capacity analysis}

First, investigate the shortest distance between the traffic according to city of Yunnan department of transportation web site (see Table 1).

Table 1 The shortest distance $D_{i j}(k m)$ between the traffic in the city in Yunnan Province

\begin{tabular}{|c|c|c|c|c|}
\hline City & Kunming & Qujing & Yuxi & Chuxiong \\
\hline Kunming & -- & 137 & 88 & 157 \\
\hline Qujing & & -- & 221 & 293 \\
\hline Yuxi & & & -- & 242 \\
\hline Chuxiong & & & & -- \\
\hline
\end{tabular}

Data source: Network Highway Bureau of Yunnan province highway mileage

Calculated according to a formula drawn up coefficient coefficient ai accessibility between cities was shown in Table 2.

Table 2 City accessibility coefficient $a_{i}$

\begin{tabular}{|c|c|c|c|c|}
\hline City & Kunming & Qujing & Yuxi & Chuxiong \\
\hline Kunming & -- & 0.93 & 1.45 & 0.87 \\
\hline Qujing & & -- & 0.91 & 0.68 \\
\hline Yuxi & & & -- & 0.74 \\
\hline Chuxiong & & & & -- \\
\hline
\end{tabular}

Note: data from 《the statistical yearbook of Yunnan》

As can be seen from Table 2, the integrated value of the accessibility factor in Kunming City in a maximum of $43.25,3.1$ second Yuxi, Qujing 2.52, Chuxiong minimum of 2.28. The reason is located in Kunming city center 4, and 3 from the other prefectures are close, and the most economically developed, the most comprehensive transport infrastructure, the highest level road. While the other three in the city of Kunming all these areas compared with the weak. Development Report from the Economic and Social Yunnan City 4 can be calculated in Central City (4 City) non-agricultural population and urban GDP (see Table 3)

Table 3 Urban non-agricultural population and GDP

\begin{tabular}{|c|c|c|c|c|}
\hline City & Kunming & Qujing & Yuxi & Chuxiong \\
\hline $\begin{array}{c}\text { Non agricultural } \\
\text { population / } \\
\text { person }\end{array}$ & $447.7 * 104$ & $248.46 * 104$ & $103.2 * 104$ & $73.2 * 104$ \\
\hline GDP/ yuan & $\begin{array}{c}3415.31 * 10 \\
8\end{array}$ & $\begin{array}{c}1583.94 * 10 \\
8\end{array}$ & $\begin{array}{c}1102.5 * 10 \\
8\end{array}$ & $\begin{array}{c}632.5 * 10 \\
8\end{array}$ \\
\hline
\end{tabular}

Note: data from 《the statistical yearbook of Yunnan》

\section{Development of industry structure}

As can be seen from Table 4, industrial economic zone in central Yunnan is still occupying the most important economic growth pulling power, but the total value of industrial production in central Yunnan economic zone did not increase the proportion of GDP, but tends to decrease. The industrial structure of the entire central Yunnan economic area is still two, in the form of three and one, indicating that the economic zone in central Yunnan and did not enter a higher diffusion effect city.

Table 4. Changes of industrial structure in Yunnan economic zone

\begin{tabular}{|c|c|}
\hline Years & $\begin{array}{c}\text { Changes of industrial structure in Yunnan Economic } \\
\text { Zone }\end{array}$ \\
\hline
\end{tabular}




\begin{tabular}{|l|l|}
\hline 2003 & $13: 50: 37$ \\
\hline 2004 & $12: 52: 36$ \\
\hline 2005 & $13: 48: 39$ \\
\hline 2006 & $12: 50: 38$ \\
\hline 2007 & $12: 49: 39$ \\
\hline 2008 & $12: 50: 38$ \\
\hline 2009 & $11: 48: 41$ \\
\hline 2010 & $11: 50: 39$ \\
\hline 2011 & $11: 51: 38$ \\
\hline 2012 & $11: 50: 39$ \\
\hline 2013 & $11: 49: 40$ \\
\hline
\end{tabular}

Regional economic development is inseparable from the region's overall planning, division of labor in the economic zone of the cities in China is to rely more overall plan of government, it turns out that the Chinese government in the overall planning of the regional economic development of the region is carried out very effective. Therefore, the development in Central District 4 cities need a guide to do the overall planning, in order to avoid wasting resources in the development of the economic zone in central Yunnan. When planning the Yunnan provincial government in Yunnan Kunming Economic Area and the establishment of central Yunnan Economic Area Economic Development Leading Group, the leading group comprising members of the leadership of the provincial government and the city of Yunnan 4, aimed at developing the economy enables Yunnan Yunnan District 4 city administratively timely coordination and communication. Promote the development of Yunnan 4 cities 4 city government personnel must establish a new performance concept, reform the old performance evaluation methods and performance assessment indicators, not to develop a single city as the content of the performance assessment.

\section{Summary}

The accumulation of human capital, configuration, and incentives put forward some suggestions to improve the competitiveness of industry gathering in Central area. Economic development of the economic zone in central Yunnan has been the dominant force in the economic development of Yunnan Province, and the integration of economic progress in Central City area has an important role in its economic development. Spatial Information Integration in Central City and its economic zone between relevant. Therefore, from the perspective of regional economic ties, taking the urban space in Central City linked to capacity as the starting point, Gravity correction model in Kunming, Qujing, Yuxi, Chuxiong space contact was the ability to measure, analyze and from cities in Central City under the influence of the elements of spatial connection status and the ability to link the ability of space to make recommendations about the city location, infrastructure regional division of labor, industrial layout, regional cooperation of the executive branch.

\section{References}

[1] Getz D. Event tourism: concepts, international case studies, and research[M]. Cognizant Communication Corporation, 2013.

[2] Juan Z. On Translating Chinese Internet Buzzwords into English from the Perspective of Skopos Theory: Taking the Example of 2012 Chinese Internet Buzzwords[J]. Journal of Hubei Engineering University, 2013, 2: 017.

[3] Chen H. Research on Literary Translation Capability and the Construction of Training Mode[C]//2015 International Conference on Education Technology and Economic Management. Atlantis Press, 2015.

[4] Olson E M, Duray R, Cooper C, et al. Strategy, structure, and culture within the English Premier 
League: an examination of large clubs[J]. Sport, Business and Management: An International Journal, 2016, 6(1).

[5] Zhang Z. Chinese and Canadian teachers implement a hybrid Sino-Canadian curriculum: A multiliteracies perspective[J]. Teaching and Teacher Education, 2015, 48: 106-116.

[6] Underwood P R. Teacher beliefs and intentions regarding the instruction of English grammar under national curriculum reforms: A Theory of Planned Behaviour perspective[J]. Teaching and Teacher education, 2012, 28(6): 911-925.

[7] Law R, Buhalis D, Cobanoglu C. Progress on information and communication technologies in hospitality and tourism[J]. International Journal of Contemporary Hospitality Management, 2014, 26(5): 727-750.

[8] Al-Issa A S M. Making a Case for New Directions in English Language Teaching Research at an Omani University: A Critical Qualitative Content Analysis Report[J]. The Qualitative Report, 2015, 20(5): 560 .

[9] Liu D, Li L. Analysis of the science development of the PST-CCE in applied undergraduate colleges and universities [J]. 2015.

[10]El-Gohary H. Factors affecting E-Marketing adoption and implementation in tourism firms: An empirical investigation of Egyptian small tourism organisations[J]. Tourism Management, 2012, 33(5): 1256-1269. 